\begin{tabular}{l|c|c|c|c|} 
DOI: http://dx.doi.org/10.54085/ap.covid19.2021.10.2.8 \\
Annals of Phytomedicine: An International Journal \\
http://www.ukaazpublications.com/publications/index.php \\
Print ISSN : 2278-9839
\end{tabular}

\title{
COVID-19: Risks on animal health, phytochemical approach for prevention and impact on livestock sector: A short review
}

\author{
Aditya Baruah, Manoj Kr. Kalita, L. Sanathoi Khuman, Kandarpa Boruah, Ankita Gogoi, Gautam Bordoloi and Sanjib \\ Khargharia \\ Lakhimpur College of Veterinary Science, Assam Agricultural University, Joyhing-787051, North Lakhimpur, Assam, India
}

\section{Article Info}

Article history

Received 10 September 2021

Revised 27 October 2021

Accepted 29 October 2021

Published Online 30 December 2021

Keywords
Livestock
Phytochemical
Pandemic
COVID-19

\section{Introduction}

With the beginning of Chinese New Year, news emerged of an outbreak of respiratory illness of unknown aetiology in Wuhan, China which was later termed as coronavirus disease 2019 (COVID-19), caused by severe acute respiratory syndrome coronavirus 2 (SARS-CoV-2) and rapidly spread to most of the countries and became a large-scale pandemic (Zhu et al., 2020). Since its first occurrence, it had infected more than 100 million people till date which resulted in more than 2 million deaths worldwide (Song et al., 2020; WHO, 2020) which is still increasing in counts hourly. For prevention and control in human, other than treatment of symptomatic patients, various measures include monitoring of asymptomatic infections, follow-up and monitoring after disease recovery and discharge, close contact tracking, high-risk population screening, and use of disinfectants to destroy the source, but the only effective and possible way for the radical control of COVID-19 infection is by effective vaccination (Bauer $e t$ $a l ., 2021)$. Several vaccines with varying efficacy and safety were produced worldwide and were used by the global population through vaccination drives by respective nations (Kyriakidis et al., 2021). In recent years, animal welfare during disease outbreaks has received considerable attention throughout the world, raising concerns over humane options for impacted animals. Therefore, there is an urgent need to recognize the possible threats and attempts be made to

Corresponding author: Dr. Sanjib Khargharia

Assistant Professor, Department of Pharmacology, Lakhimpur College of Veterinary Science, Assam Agricultural University, Joyhing787051, North Lakhimpur, Assam, India.

E-mail: sanjibkharghoria@yahoo.com

Tel.: +91-7002425173

Copyright () 2021 Ukaaz Publications. All rights reserved.

Email: ukaaz@yahoo.com; Website: www.ukaazpublications.com lessen the negative impacts on the human as well as livestock (production systems). Hence, understanding different strategies in key sectors that contributes immunity to the human and livestock and food security, nutrition and livelihood to the world's most vulnerable populations.

\section{COVID-19 on animal health}

It is well known now that COVID-19 is not restricted to human populations only; reports of increasing positive cases in animals are also observed. The first report in animals was infection in a 4-years old female tiger 'Nadia' at the Bronx Zoo in United States possibly after contracting with an asymptomatic employee (BBC News, 2020). The zoo veterinarians ran a number of diagnostic tests on her who exhibited symptoms of respiratory difficulties and other issues before considering it as coronavirus infection. In India, first reported death of animal due to COVID-19 infection was nine-year-old lioness, named Neela on June 3, 2021 at Arignar Anna Zoological Park (India Times, 2021). In Coimbatore and Nilgiris, from two camps the Forest Department collected swab samples to test 56 numbers of captive elephants (NDTV, 2021). This decision to test the elephants came only after nine Asiatic lions at the Vandalur zoo were tested positive for COVID-19 and one of them died of the infection (Hindu, 2021). These incidences surprised the whole world because in 2002 SARS pandemic, no animals were infected (Seattle Times, 2021). The University of Tennessee collected biological samples from 75 captive felids for detection of feline corona virus (FCoV) gene. The findings revealed that over half of the felids in these tests were found positive for FCoV infection by either genetic detection or serological techniques (Kennedy et al., 2002). There were various reports suggesting that cats could be infected with SARS-CoV-2 and they could also transmit the infection to other cats under particular conditions. Ever since 
then, there has been confirmed report of infection in minks of two countries (Denmark and Netherlands), big cats kept in zoos, pet dogs, even in ferrets and also in variety of different species of animals (Mallapaty, 2021). It is also suggested that the SARS-CoV-2 virus originated from bats and evidences suggest that other species of wild animals may also be infected. However, transmission to or from companion animals that spend a lot of time in close contact with people also presents extra problems for trying to control a pandemic in humans (Science Alert, 2021). Animals could play an important role in SARS-CoV-2 disease transmission. The recently confirmed COVID-19 cases in the Netherlands due to mink could suggest that animal to human viral spillover is possible (Kiros et al., 2020). In the current pandemic, the situation is rapidly evolving and in light of the recent evidence, people should be aware of the potentiality of COVID-19 infection to humans from animals which are in close proximity with humans such as pets and other domesticated animals. Therefore, the usual precautionary measures should always be there as one part of a disease prevention strategy when dealing or spending time with companion animals. It is imperative that the pets infected with SARS-CoV-2 is detected, particularly those whose owners has been tested positive as well as subsequent isolation of such cases to prevent the recurrence of COVID-19. Along with other successful management of the pandemic, it is very critical to conduct further studies on the overall zoonotic risks of SARS-CoV- 2 (Calvet et al., 2021) as well as on the putative intermediate host, so that the re-emergence of the virus may be prevented. Furthermore, all countries must enhance their strategy firmly as means of legislation for animal epidemic prevention and control like Netherlands, Spain, USA and China who have already adopted. The development of vaccine for mitigating effects of COVID19 or SARS-CoV-2 virus to the animal sector is also one of the important factors. Russia had registered world's first corona virus vaccine for animals, describing the step as important to disrupting mutations. The vaccine called Carnivak-Cov had been tested beginning October, 2020 on dogs, cats, mink, foxes and other animals and was proven to be effective (Times of India, 2020).

Currently numbers of vaccines against bovine corona virus have been successfully licensed in the United States of America. The disease occurs in calves within a few days of birth, it is essential that these vaccines work very rapidly. As it affects the young calves, the vaccines are thereby given to cows before calving as the antibodies which are present in the colostrums will find its way into the calf and provide it with passive immunity. On the other hand, the calves which are one day old or a few days old may be provided with intranasal vaccines. This intranasal vaccine induces an immediate onset of protection against the virus as it induces innate immune response followed by production of interferons. As per epidemiological studies the protection of the cattle against the disease correlate with the serum neutralizing as well as the levels of haemagglutinating antibodies (Ian, 2020). Very recently, the State Department of Agriculture, Trade and Consumer Protection of USA approved the use of a vaccine for mink made by veterinary pharmaceutical company, Zoetis, in May, 2021 for experimental use against SARS-CoV-2 (WPR, 2021). The unique combination of antigen and carrier ensure safety and efficacy for the species in which a vaccine is used. After application of many years of experience, scientists from the Zoetis' research and development, Michigan were able to develop vaccines for other corona viruses specially for poultry, dogs and cattle. The specialty of the Zoetis' COVID-19 vaccine is that it is formulated specifically for animal species. The virus that is used for formulation of this vaccine is the same with that of the human vaccine. However, the carrier or the adjuvant that is used in animal vaccine differs from that of the human vaccine. A real time polymerase chain reaction (PCR) has been developed by Zoetis to detect the presence of SARS-CoV-2 specifically in feline and canine has been validated which shall further support the veterinarians of the globe in preventing the disease transmission (Zoetis, 2021).

\section{Application of phytochemical against COVID-19 in animals}

Plant based antiviral products with little known side effects and also with enhance immunomodulatory effects can be used to fight against COVID-19, both in human as well as in animal. An initial protection against the virus may be conferred by phytochemicals with their anti-inflammatory, antiviral and immunomodulatory properties. There is abundance of naturally available medicinal plants with some health benefits in India recommended by AYUSH (Khan et al., 2020). The leaves of tulsi plant are a versatile herb with immense medicinal values and are used to manage various ailments like pain, fever, cough and cold as well as diarrhoea since ancient times. Proven antiviral efficacy of tulsi is reported for animal viruses such as vaccinia virus, newcastle disease virus and infectious bursal disease virus (Prakash and Gupta, 2005). Studies suggest that the phenolic contents in tulsi which provides antioxidant properties are beneficial in respiratory disorders like cough and cold, bronchitis, asthma, and influenza (Shivananjappa and Joshi, 2012) and may be helpful in combating SARS-CoV-2 viral load.The plant derived phytochemicals (particularly polyphenols) with putative active substances such as flavonoids, gallates, and quercetins, are potent inhibitors to prevent the proliferation of the COVID-19 inducing coronavirus (Youssef $e t$ al., 2020). Biflavonoids from Torreya nucifera inhibits the replication of SARS-CoV-2 CL pro irrespective of human and animals. Senna alata, a large flowering plant is currently being used for treatment of flu, fever, malaria and other medical conditions due to presence of active compounds like quinines, alkaloids and terpenes may helpful for prevention of corona virus infection.

Aromatic plants and herbs downregulate the pre-inflammatory mediators, namely; IL-1, 6, 10 and 18, TNF-alpha and NF-kappa $\mathrm{B}$ associated with the cytokine storm in case of COVID-19, which has proved to be deadly. Concurrently, uses of several medicinal plants (Tinospora cordifolia, Ocimum sanctum Linn. etc.) extract enhancement of expression of nitric oxide synthase, production of IgG, IFN-gamma and IL-4 and activation of T helper cells, and NK cells, promises to provide protection along with therapeutic potential. These can be contribution in enhancing the body's immune system along with strengthening and maintaining the health of the respiratory tract, the preferred host for the SARS-CoV-2 (Mehrotra, 2020). In other hand spices like ginger, cumin, cloves, turmeric, garlic, etc., contain polyphenols, flavonoids, saponins and alkaloids. The antioxidant, anti-inflammatory and immunomodulatory effects of spices can potentiate health functionality by acting on various pathological processes (Palai et al., 2020). The risks of coronavirus (COVID-19) can be mitigated with a special reference the respiratory health by the use of these spices every day, which strengthens the natural protection mechanism (immunity) of the body.

Herbal remedy programs issued by the China Health Authority to prevent the spread of COVID-19 included the use of two herbal 
medicinal formulas from Radix astragali (Huangqi) and Glycyrrhizae radix Et Rhizoma (Gancao), which was proven successful and could be implemented for both human and animal health (Youssef $e t$ al., 2020). Roots of licorice plant exhibits some bioactive properties like antitumoral, anti-inflammatory, and antiviral effects on both animal as well as human health. Glycyrrhizic acid (glycyrrhizin, GL) and its aglycone glycyrrhetinic acid (GLA) has also shown in vitro efficacy against a large number of viruses such as herpes virus, flavivirus, Hepatitis $\mathrm{C}$ virus, human immunodeficiency virus, and SARS coronavirus (SARS-CoV). Inhibition of viral proliferation is demonstrated with these components in vero cell lines and in patients. Sugar moieties in the glycyrrhizic acid are responsible for the antiSARS activity, as it is seen that a replacement of these with functional groups resulted in a loss in activity. Herbs used earlier to block SARS could also successfully inhibit SARS-CoV-2 infection. To explore this, Wen et al. (2011) examined the extracts from over 50 traditional Chinese medicinal herbs on anti-SARS-CoV activity using a Vero E6 cell-based cytopathogenic effect assay. This outcome of the study revealed that six novel extracts may be used as potential SARS-CoV drug targets. These herbal extracts were derived from plants like Rhizoma cibotii, Gentianae radix, Dioscoreae rhizoma, Cassiae semen, and Loranthi ramus; all of them inhibited SARS-CoV replication, and two of them inhibited virus protease activity(Ul Qamar et al., 2020).

\section{Development on plant based recombinant vaccines}

Researchers throughout the globe have given significant efforts to design and develop effective vaccines and antiviral therapeutic drugs to curb the spread of COVID-19. Molecular farming is a term to describe the use of plants for production of recombinant vaccines and drugs which has been used for more than 30 years (Takeyama et $a l ., 2015)$. The synthesis of desirable recombinant proteins (pharmaceuticals and industrial proteins) using whole plants or in vitro cultured plant tissues/cells in large-scale bioreactors is termed molecular farming. Plant secondary metabolites have significant biological and ecological functions in chemical defense because of their antioxidative and antimicrobial activities. Apart from production of recombinant plant vaccines, molecular farming can also be used for the large-scale production of these secondary metabolites from plants. These plant based biological products are comparatively stable, safe, effective, easily available, and affordable. Plant molecular farming could facilitate an accelerated rate of production of these biologicals on industrial scale, and has the potential to fulfill emergency needs, as in the present situation of COVID-19 pandemic (Dhama et al., 2020). Plants possess a greater ability to act as bioreactor system which supports many important biological processes including viruslike particles (VLPs) and vaccines. Transformation of plants with foreign genes leads to production of protein drugs, vaccines, and antibodies against different human as well as animal pathogens. As a result, plants make it simple to store protein vaccines and medications in a safe, cost-effective and trouble-free manner. Advantages of plantbased reactors are: (i) lower cost in maintenance; (ii) lower risks of contamination from animal pathogens; (iii) competence to implement modifications in eukaryotic post-translational machinery function; and (iv) being amenable to the large-scale manufacturing process. Initial works were done to produce plant-based vaccines by expressing antibodies using tobacco plants. The world's first plant-based vaccine approved for the newcastle disease virus (NDV) by the United States Department of Agriculture (USDA) is for poultry. It confers more than $90 \%$ protective efficiency in chicken, following the challenges faced with NDV (Shahid et al., 2020). The only other plant-based product licensed is the plant-made single-chain fragment variable monoclonal antibody ( $\mathrm{scFv} \mathrm{mAb})$ used for the production of a recombinant Hepatitis B virus (HBV) vaccine in Cuba. Few examples of plant-made vaccines and therapeutics produced through molecular farming methods include vaccines to combat cholera, dengue fever virus and HBV, monoclonal antibodies to HIV, Ebola also helps in treatment of patients suffering with gaucher disease by providing glucocerebrsidase which is the therapeutic agent for the disease. Several molecular farming companies and research laboratories have taken up the challenge to combat COVID-19 and to meet up the shortage of COVID-19 detection tests that could be alleviated by producing diagnostic agents in plants. Plant based vaccines have a huge potential and may play an important role in transforming the field of vaccine production. Considering the future prospects and demands, these plant-based vaccines have the potential to revolutionize the field of vaccinology. This highlights the development, production, and use of plant-based vaccines and antibodies as a mitigation strategy to combat COVID-19 pandemics (Mahmood et $a l ., 2020)$ in near future.

\section{Impact of COVID-19 in livestock and poultry sector}

There has been an important impact on livestock and poultry production and its supply due to adverse effect of COVID-19 pandemic which has mostly affected the availability of livestock as well as poultry products for daily consumption by the public (Biswal et al., 2020). The prime issue arising during the pandemic was the lack of marketing opportunity, which enforced the possession of the animals for longer period beyond the marketing age. It has led to an increased economic loss to the farmers as they had to feed the animals beyond the marketable weight. Limited access to livestock feed due to restricted transportation and lockdown measures were a major cause of concern for the livestock farmers. Restrictions in movement and the disruption of trade both import and export has cut the access of farmers to breeding as well as replacement stock (e.g., day old chick, heifers, piglets, gilts and semen of different species) (FAO, 2020). Many developing countries including large parts of Africa and Middle East depend on imports of livestock and poultry products. Thereby, import restrictions had a greater impact on its consumption, which has affected both the producers and consumers of the world. The small-scale producers have been adversely affected due to the closure of daily live markets (Aday and Aday, 2020) where they sell their produces. Due to logistical issues, there has been drop in demand and reduced sale leading to lowering of prices. This has resulted in dumping of products or keeping their stocks for longer period of time, which has led to higher production rate and heavy economical loss. In developing nations, small animals or poultry are primarily reared by women which acts an essential source of income which is directed towards purchase of essential commodities as well as for fulfilling nutritional requirements is disrupts. Along with the decrease in livestock production, the COVID19 pandemic had a significant adverse effect on the supply chain. Movement restriction and disruption has impacted the role of intermediaries/middle man who play a vital role in collecting animals and their produces from small scale farms to the market. The disruption of this network has thereby made the farmers lose their link with the larger buyers who sell the produces. The disruption of animal health extension services combined with interruption of the 
delivery and use of vaccines and medicines has increased the likelihood of occurrence of future epizootics that may cause major livestock losses and outbreaks of diseases. Various activities such as vaccination, treatment of sick animals and bio-security have been adversely affected due to shortage of labour which has reduced the capacity to work on such activities. Due to the restricted movement, the farmers have not been able to avail veterinary services and health inputs and challenges developed for veterinary and veterinary professionals to visit the farms due to COVID-19 protocols (Slabodkin, 2020; Herper and Branswell, 2020).

Following the nation wide lockdown, the closures of dairy food outlets, restaurants, hotels as well as the prohibition of all types of social and cultural programs, had sharply decreased the market demand for milk, eggs, meat and its byproducts. Milk being a perishable food product, it encountered with troubles as the milk marketing channels were badly affected. As reported farmers had to throw their farm produce milk on the streets as a symbolic protest since they were not able to sell their produces in the market (The Financial Express, 2020). There has been a reduction in the purchasing power of the people which has led to reduced public procurement. The imposing of various containment or lockdown measures has led to people losing their jobs rendering millions in the world unemployed. With the incidence of COVID-19, the dairy industry in India and developing countries has suffered significantly due to the reduced overall demand of about $25-30 \%$ in the country, at least during first quarter after the lockdown from March 2020 onwards (Shashidhar, 2020).

In India, the poultry industry was one of the initial victims of misconception of COVID-19, where various social media posts linked chicken consumption with contraction of coronavirus infection. The impact on poultry and allied industry was analysed and documented properly several states of India in Table 1 (Kolluri et al., 2021). The industry saw the demand for chicken and eggs fall by $30 \%$ to $40 \%$. Farmers resorted to distress sale and some had culled the birds. Though, the market recovered in the first half of 2021, poultry industry representatives say that the industry continues to be in the red across the country. The poultry industry alone suffers loses around Rs. 22,000 crores during COVID-19 crisis (Kurmantah, 2021). The poultry industry and allied sector also reported drop in sale of livestocks' rearing equipment and feed. Now, that these misconception has been cleared after poultry industry and government launched massive awareness campaigns that consumptions of poultry meat do not cause COVID-19 infection and it additionally provides adequate protein to the human body that is essential in producing immunity in the body during COVID-19 infection. Global trade and cooperation will help administrations around the world to synchronize their existing legislation relating to markets, disease control, poultry nutrition, and drug and vaccine licensing of veterinary profession, especially after the COVID-19 pandemic. Consumers' desire for highquality meat products will strongly influence production practices so breeders, veterinarians, farmers and all other partners involved in the meat and poultry industry chain should share more tasks to strengthen the industry. Biosecurity, hygiene, immunity are the first lines of defense, perhaps the biggest lesson globe has learned from the COVID-19 (Garcia, 2020) pandemic as well SARS-CoV-2 virus (COVID-19) is not associated with livestock, poultry or associated products. The COVID-19 pandemic has given a lesson to take global health as one unit. Similarly, there is an urgent need for the meat and poultry industry to unify its health and biosecurity systems as one unit. Improve protection, prevention and control programs in livestock and poultry farms ensure product quality and implement new programs to prevent the transmission of zoonotic diseases and development of risk free phytomedicine which enhance the innate immunity of animals as the first line of disease prevention and control.

Table 1: Price (US Dollar) trend of various poultry entities during COVID-19 pandemic 2020 (Copied from Kolluri et al., 2021).

\begin{tabular}{|l|c|c|c|c|}
\hline Parameter & January & February & March & April \\
\hline \multicolumn{5}{|c|}{ Production cost } \\
\hline Live broiler (kg) & 0.90 & 0.84 & 0.79 & 0.87 \\
Table eggs (per 100) & 5.00 & 5.00 & 4.00 & 4.00 \\
Fertile eggs (per 100) & 20.00 & 20.00 & 20.00 & 20.00 \\
\hline
\end{tabular}

Farm gate prices of broilers (per kg live weight)

\begin{tabular}{|l|c|c|c|c|}
\hline Andhra Pradesh & 1.22 & 0.77 & 0.35 & 1.00 \\
Telangana & 1.17 & 0.74 & 0.36 & 0.93 \\
Tamil Nadu & 1.23 & 0.90 & 0.56 & 1.15 \\
Maharashtra & 1.12 & 0.69 & 0.34 & 0.99 \\
Uttar Pradesh & 1.33 & 0.80 & 0.66 & 0.66 \\
Overall mean price & 1.0 & 0.27 & 0.14 & 0.68 \\
Dressed chicken (kg) & 2.03 & 1.36 & 0.68 & 2.71 \\
\hline \multicolumn{5}{|c|}{ Prevailing sale price of table eggs (per 100) } \\
\hline East Godavari & 6.08 & 5.01 & 4.34 & 4.69 \\
Hyderabad & 5.67 & 4.80 & 4.00 & 5.03 \\
Namakkal & 5.61 & 5.15 & 4.10 & 5.43 \\
Pune & 6.57 & 5.61 & 4.76 & 5.74 \\
Kolkata & 6.54 & 5.40 & 5.00 & 4.91 \\
Overall mean price & 6.00 & 5.00 & 4.00 & 5.00 \\
Fertile eggs (per 100) & 20.00 & 19.00 & 10.00 & 16.00 \\
Broiler feed cost (kg) & 0.39 & 0.38 & 0.37 & 0.36 \\
Layer feed cost (kg) & 0.29 & 0.27 & 0.26 & 0.25 \\
\hline \multicolumn{5}{|c|}{ Calculated price indices } \\
\hline Broiler price index & $107.30^{\mathrm{a}}$ & $69.09^{\mathrm{b}}$ & $40.58^{\mathrm{c}}$ & $83.44^{\mathrm{b}}$ \\
Egg price index & $97.18^{\mathrm{a}}$ & $79.30^{\mathrm{b}}$ & $67.25^{\mathrm{c}}$ & $75.78^{\mathrm{b}, \mathrm{c}}$ \\
\hline \multicolumn{5}{|c|}{ Maize (feed-grade) prices } \\
\hline Projected & 27.21 & 26.53 & 21.77 & 20.45 \\
Realized & 27.49 & 24.72 & 19.49 & 18.91 \\
\hline
\end{tabular}

a,b,c Means with different superscripts within rows differ significantly $(P<0.05)$. 


\section{Conclusion}

The COVID-19 pandemic has taught the entire world that research must continue and be redirected to uncover new vaccines. For human as well as animals, quick and affordable diagnostic tools and additional methods for disease prevention are essential in which phytochemical may play a major role in future. Research and development in the identification and control of livestock and poultry diseases should not be limited to currently known diseases apart from human counterpart. It must be potent and integrated with emerging zoonotic diseases that may require new vaccines to control them. Continuing education programs should be implemented at all levels of the livestock industry and should be renewed in specified time. The whole world is now almost paralyzed for almost two years by coronavirus. It goes without saying that the big catastrophe is coming in the economy. If this situation is prolonged, food crisis will start globally. The most pressing need at the moment to focus is in the livestock sector including development of phytochemical, agriculture for sustainable health approach in human being.

\section{Acknowledgements}

We would like to thank Dr. Karuna Saikia, Dr. Prasanta Chabukdhara and Dr. Dwipjyoti Mahanta of Lakhimpur College of Veterinary Science for their technical and moral support.

\section{Conflict of interest}

The authors declare no conflicts of interest relevant to this article.

\section{References}

Aday, S. and Aday, M.S. (2020). M.S. Impact of COVID-19 on the food supply chain, Food Quality and Safety, 4(4):167-180

Bauer, S.; Contreras, S.; Dehning, J.; Linden, M.; Iftekhar, E. and Mohr, S.B. (2021). Relaxing restrictions at the pace of vaccination increases freedom and guards against further COVID-19 waves. PLoS Comput. Biol., 17(9):e1009288.

BBC News, (2020). Coronavirus: Tiger at Bronx Zoo tests positive for COVID-19.https://www.bbc.com/news/world-us-canada-52177586, April 6.

Biswal, J.; Vijayalakshmy, K. and Rahman, H. (2020). Impact of COVID-19 and associated lockdown on livestock and poultry sectors in India. Vet. World, 13(9):1928-1933.

Calvet, G.A.; Pereira, S.A.; Ogrzewalska, M.; Pauvolid-Correa, A.; Resende, P.C and Tassinari, W.S. (2021). Investigation of SARS-CoV-2 infection in dogs and cats of humans diagnosed with COVID-19 in Rio de Janeiro, Brazil. PLoS ONE, 16(4):e0250853.

Dhama, K.; Natesan, S.; Yatoo, M.I.; Patel, S.K.; Tiwari, R.; Saxena, S.K. and Harpan, H. (2020). Plant-based vaccines and antibodies to combat COVID-19: Current status and prospects. Human Vaccine Immunother., pp:1-8.

FAO, (2020). Mitigating the impacts of COVID-19 on the livestock sector Rome.

Garcia, L.F. (2020). Immune response, inflammation, and the clinical spectrum of COVID-19. Front. Immunol., 11:14-41.

Herper, M. and Branswell, H. (2020). Shortage of crucial chemicals creates new obstacle to U.S. coronavirus testing. STAT, 10 March 2020. [online]. https://www.statnews.com/2020/03/10/shortage-crucial chemicals-us-coronavirus-testing/
Hindu, (2021). https://www.thehindu.com/news/national/tamil-nadu/ elephants-at-theppakadu-camp-tested-for-covid-19/ article34758818.ece

Ian, R. (2020). Vaccination against coronaviruses in domestic animals. Vaccine, 38:5123-5130.

India Times, (2021). https://www.indiatimes.com/news/india/after-deathof-a-lioness-from-covid-19-tamil-nadu-tests-56-captive-elephantsin-two-camps-542271.html

Kennedy, M.; Citino, S.; McNabb, A.H.; Moffatt, A.S.; Gertz, K. and Kania, S. (2002) Detection of feline coronavirus in captive Felidae in the USA. J. Vet. Diagn. Invest., 14:520-522.

Khan, A.A.; Khan, S.; Khan, U. and Das, K. (2020). The COVID-19 pandemic: A scoping review. Annals of Phytomedicine, 9(1):18-26.

Kiros, M.; Andualem, H.; Kiros, T.; Hailemichael, W.; Getu, S.; Geteneh, A.; Alemu, D. and Abegaz, W.E. (2020). COVID-19 pandemic: current knowledge about the role of pets and other animals in disease transmission. Virology J., 17:143.

Kolluri, G.; Tyagi, J.S. and Sasidhar, P.V.K. (2021). Research Note: Indian poultry industry vis-à-vis coronavirus disease 2019: A situation analysis report. Poultry Sci., 100(3):1-5.

Kurmanath, K. V. (2021). Poultry sector suffers Rs 22000 crore loss due to Covid-19. Hindu, Hyderabad Edition, September 28.

Kyriakidis, N.C.; Lopez-Cortes, A. and Gonzalez, E.V. (2021). SARS-CoV-2 vaccines strategies: A comprehensive review of phase 3 candidates. Vaccines, 6:28.

Mahmood, N.; Nasir, S.B. and Hefferon, K. (2020). Plant-based drugs and vaccines for COVID-19. Vaccines (Basel), 9(1):15.

Mallapaty, S. (2021). The search for animals harbouring coronavirus and why it matters. Nature, 591:26-28.

Mehrotra, N. (2020). Medicinal plants, aromatic herbs and spices as potent immunity defenders: Antiviral (COVID-19) perspectives. Ann. Phytomed., 9(2):30-49.

NDTV, (2021). 56 Elephants in two Tamil Nadu Camps Undergo COVID-19 Tests: Report.https://www.ndtv.com/tamil-nadu-news/56-elephantsin-two-camps-in-tamil-nadu-undergo-covid-19-tests-2459274. June 9.

Palai, S.; Dehuri, M. and Patra, R. (2020). Spices boosting immunity in COVID19. Ann. Phytomed., 9(2):80-96.

Prakash, P. and Gupta, N. (2005). Therapeutic uses of Ocimum sanctum Linn (Tulsi) with a note on eugenol and its pharmacological actions: A short review. Indian J. Physiology and Pharmacology, 49(2):125131 .

Science Alert, (2021). 9 August, 2021.https://www.sciencealert.com/ascientist-explains-what-would-happen-if-a-more-lethal-covidstrain-in-pets-emerged

Seattle Times, (2021). https://www.seattletimes.com/nation-world/bronxzoo-tiger-is-first-u-s-animal-to-test-positive-for-coronavirus.

Shahid, N.; Samiullah, T.R.; Shakoor, S.; Latif, A.; Yasmeen, A.; Azam, S.; Shahid, A.A.; Husnain, T. and Rao, A.Q. (2020). Early stage development of a newcastle disease vaccine candidate in corn. Front. Vet. Sci., 24(7):499.

Shashidhar, A. (2020). Coronavirus impact: Dairy industry faces $30 \%$ dip in demand. Business Today Available from: https://www.businessto day.in/current/corporate/coronavirus-impact-dairy-industry-faces30 dip-in-demand/ story/400517.html. Retrieved on 18-04-2020). 
Shivananjappa, M. and Joshi, M. (2012). Aqueous extract of tulsi (Ocimum sanctum) enhances endogenous antioxidant defenses of human hepatoma cell line (HepG2). Journal of Herbs, Spices and Medicinal Plants, 18(4):331-348.

Slabodkin, G. (2020). FDA chief warns of supply 'pressure' on reagents for coronavirus tests. Medtechdive, 12 March 2020. [online]. https:// www.medtechdive.com/news/fda-chief-warns-ofsupply-pressure-onreagents-for-coronavirus-tests/573999/

Song, F.; Shi, N. and Shan, F. (2020). Emerging coronavirus 2019-nCoV pneumonia. Radiology, 295:210-217.

Takeyama, N.; Kiyono, H. and Yuki, Y. (2015). Plant-based vaccines for animals and humans: Recent advances in technology and clinical trials. Ther. Adv. Vaccines, 3(5-6):139-154.

The Financial Express, (2020). Dairy Farmers in Trouble, Seek Govt Support, https://thefinancialexpress.com.bd/trade/dairy-farmers-in-troubleseek-govt-support 1585369478. (Accessed 5 February 2020).)

Times of India, (2020). https://timesofindia.indiatimes.com/world/europe/ russia-registers-worlds-first-covid-vaccine-for-animals/articleshow/ $81776095 . \mathrm{cms}$

UI Qamar, M.T.; Alqahtani, S.M. and Alamri, M.A. (2020). Chen L-L. Structural basis of SARS-CoV-2 3CLpro and anti-COVID-19 drug discovery from medicinal plants. J. Pharm. Anal., 10:313-9.
Wen, C.C.; Shyur, L.F.; Jan, J.T.; Liang P.H.; Kuo, C.J.; Arulselvan, P.; Wu, J.B.; Kuo S.C. and Yang, N.S. (2011). Traditional Chinese medicine herbal extracts of Cibotium barometz, Gentiana scabra, Dioscorea batatas, Cassia tora, and Taxillus chinensis inhibit SARS-CoV replication. J Tradit Complement Med., 1(1):41-50.

WHO, (2020). https://www.who.int/emergencies/diseases/novel-corona virus-2019/technical-guidance/naming-the-coronavirus-disease(covid-2019)-and-the-virus-that-causes-it.

WPR, (2021). https://www.wpr.org/wisconsin-farms-working-vaccinateminkagainstcoronavirus

Youssef, A.A.; Mahmoud, A.; Mayada, F.; Fatmah, M.A.; Asmaa, F. K.; Eid, A.M.; Khalid, A.A.; Noura, M.M., Manal, E. S.; Mohammed, A. A.H. and Mohamed, A. E. H. (2020). Phytogenic Products and Phytochemicals as a Candidate Strategy to Improve Tolerance to Coronavirus. Front. Vet. Sci., 7: 783.

Zhu, H.; Wei, L. and Niu, P. (2020). The novel coronavirus outbreak in Wuhan, China. Glob. Health Res.Policy. 5: 6.https://doi.org/10.1186/ s41256-020-00135-6)

Zoetis, (2021). https://news.zoetis.com/press-releases/press-release-details/ 2021/Zoetis-Donates-COVID-19-Vaccines-to-Help-Support-theHealth-of-Zoo Animals/default.aspx. 